\title{
PROJETO DE AVALIAÇÃO DE IMPACTOS, PASSIVOS E DANOS AMBIENTAIS NA REGIÃO DE ARACAJU
}

\section{IMPACT ASSESSMENT PROJECT, LIABILITIES AND ENVIRONMENTAL DAMAGE IN ARACAJU REGION}

\author{
Sabrina Nascimento \\ Universidade do Estado do Rio de Janeiro - UERJ \\ Elenice Rachid da Silva \\ Programa de Engenharia de Transportes da Coppe/UFRJ \\ Alan Jeferson de O. da Silva \\ Coordenador do GEOPROMOB \\ Josimar Ribeiro de Almeida \\ Universidade do Estado do Rio de Janeiro - UERJ \\ Universidade de São Paulo - USP
}

\section{RESUMO}

Devido ao processo rápido de crescimento urbano e populacional a Região de Aracaju tem crescido em ritmo acelerado, o que tem gerado graves impactos devido as ocupações irregulares, mas também principalmente por despejo de esgoto doméstico, lixo e pela falta de conscientização ambiental quanto a importância da preservação dos ecossistemas. Então este estudo visa avaliar o crescimento urbano com os eventos de degradação dos ecossistemas de manguezais, sendo este um ecossistema delicado que vem sofrendo com a expansão urbana desenfreada da Região de Aracaju. Pode-se constar com dados levantados que grande parte a rede de esgoto é precária, situação está que vem a se repetir até mesmo na capital, levando a concluir a necessidade de implementação de ações preventivas e conscientização ambiental para aumentar a qualidade de vida da população e tentar minimizar os danos ambientais.

Palavras-chave: Expansão urbana, Infraestrutura precária, Degradação ambiental

\section{ABSTRACT}

Due to the speedy process of urban and population growth the Aracaju Region has grown quickly, which has generated serious impacts due to irregular occupations, but also mainly by domestic sewage dump, garbage and lack of environmental awareness about the importance of preserving ecosystems. So this study aims to assess the urban growth with the events the degradation of ecosystems of mangroves, being a delicate ecosystem that has suffered from the excessive urban expansion of Aracaju Region. Can be confirm with data collected that much of the sewage network is precarious, situation that comes to repeat even in the capital, leading to the conclusion the need to implement 
preventive actions and environmental awareness to improve the quality of life of the population and try to minimize environmental damage.

Keywords: Urban expansion, Precarious infrastructure and environmental degradation

\section{INTRODUÇÃO}

Ativos ambientais são recursos naturais que são economicamente valoráveis servindo como um prestador de serviços (MMA, 1998). Então os ecossistemas fornecem ativos ambientais que vão abastecer as atividades econômicas e o crescimento populacional, e além disso esse mesmo ecossistema vai receber os resíduos gerados pela utilização dos seus recursos naturais. Sendo assim o processo de urbanização um forte fator de pressão sobre o meio ambiente, pois pode transformar um ativo ambiental em um passivo ambiental, perdendo com isso o seu valor, sendo então necessário a recuperação daquele ecossistema.

Entre os anos de 1960 a 1970, devido ao processo de industrialização do nordeste brasileiro, Aracaju ficaria contemplado com investimentos determinantes para o seu acelerado crescimento urbano e populacional (MATOS, 2010). Desde então a expansão urbana na Região de Aracaju tem crescido em ritmo acelerado, o que tem gerado graves impactos devido às ocupações irregulares e regulares sobre os ecossistemas ali existentes (FRANÇA e REZENDE, 2010), sendo esta intensa ocupação ocorrendo em áreas próximas de mangues do estuário do Rio Sergipe.

O manguezal é um importante ecossistema, pois oferece alimentação e proteção para muitas espécies (ALMEIDA e BARBIERI, 2008), sendo considerados como berçários naturais. A existência desse ecossistema está limitada somente a algumas regiões do planeta, sendo o Brasil o país com maior extensão territorial do mundo (OLIVEIRA e RODRIGUES, 2012). E esse ecossistema frágil tem sido degrado não só pelo crescimento urbano para implantações residenciais, mas também bem principalmente por despejo de esgoto doméstico, lixo e pela falta de conscientização ambiental quanto a importância deste ecossistema (ALMEIDA e BARBIERI, 2008; OLIVEIRA e RODRIGUES, 2012). 


\section{OBJETIVO}

O objetivo deste estudo é avaliar a relação do crescimento populacional, do espaço urbano, da região de Aracaju com os eventos de degradação dos ecossistemas de manguezais.

O artigo é composto por 6 seções, inclusive a introdução. Na segunda seção vai ser abortado uma a breve contextualização do local do estudo, a terceira consisti na metodologia empregada para o levantamento de dados e análises de risco apresentando um breve resumo sobre os indicadores de pressão e estado, na quarta são apresentados os resultados e discussões, na quinta seção é registrado as principais conclusões e por fim na sexta as referências bibliográficas utilizadas para compor este artigo.

\section{CONTEXTUALIZAÇÃO DO LOCAL}

Sergipe é um dos 26 estados brasileiros, sendo o estado de menor extensão territorial e localizado entre o Estado de Alagoas, ao norte, Estado da Bahia, ao sul e oeste, e entre o Oceano atlântico ao leste (Figura 1). Na zona costeira deste estado encontra-se uma importante região que tem estado em risco devido a poluição da água por esgoto doméstico e pela destruição dos manguezais, através da derrubada de árvores para a construção civil e o consumo doméstico, ação esta que atinge toda a região (ALMEIDA e BARBIERI, 2008). 
Figura 1: Localização do Estado de Sergipe

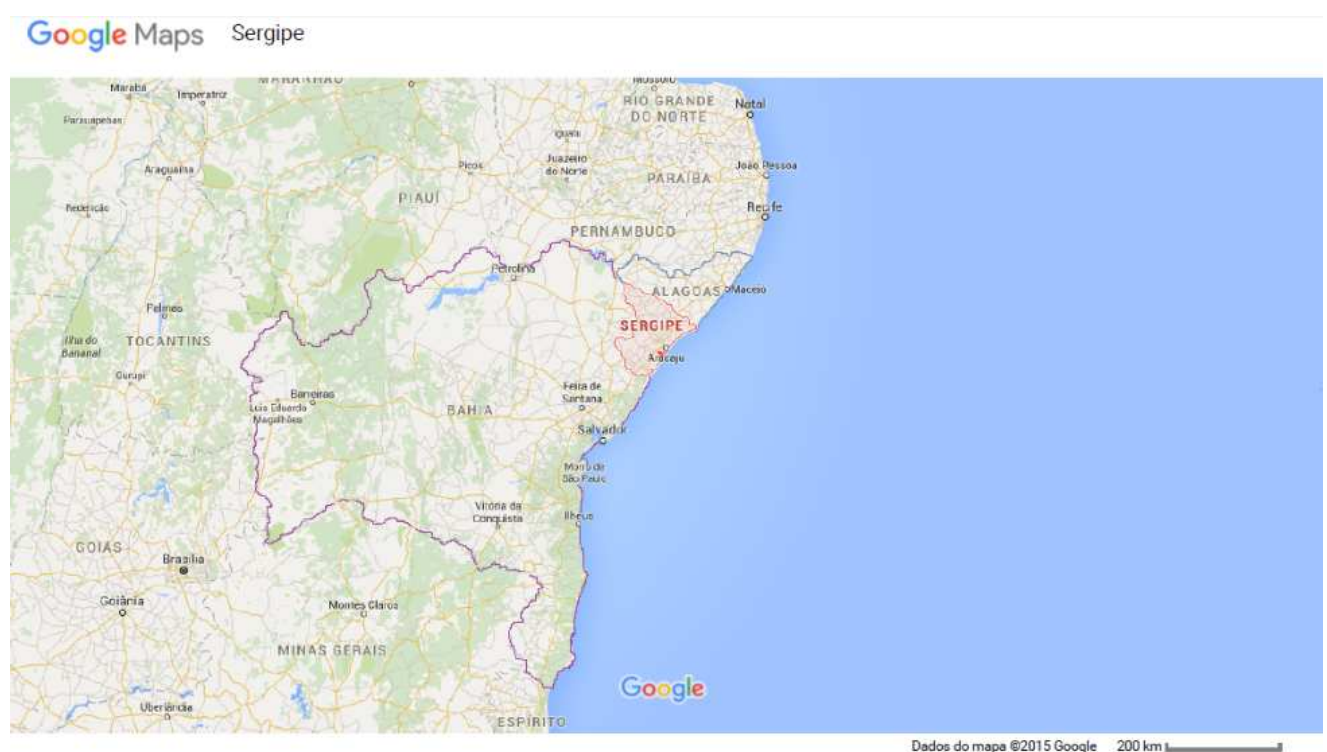

A Região de Aracaju está localizada na Zona Costeira de Sergipe. Os municípios da região são: Aracaju, Barra dos Coqueiros, Nossa Senhora do Socorro, Santo Amaro das Brotas, Laranjeiras, Maruim e São Cristóvão (Figura 2). A área abrange a foz do rio Sergipe e seus afluentes e Japaratuba, juntamente com a foz dos rios Poxim, do Sal, Catinguiba e Pomonga. Aracaju, capital do Estado de Sergipe, trata-se de uma região metropolitana que caracteriza-se por ser uma cidade estuarina (ALMEIDA e BARBIERI, 2008) com uma população estimada de 632.744 habitantes em 2015 (IBGE).

Figura 2: Municípios do Estado de Sergipe
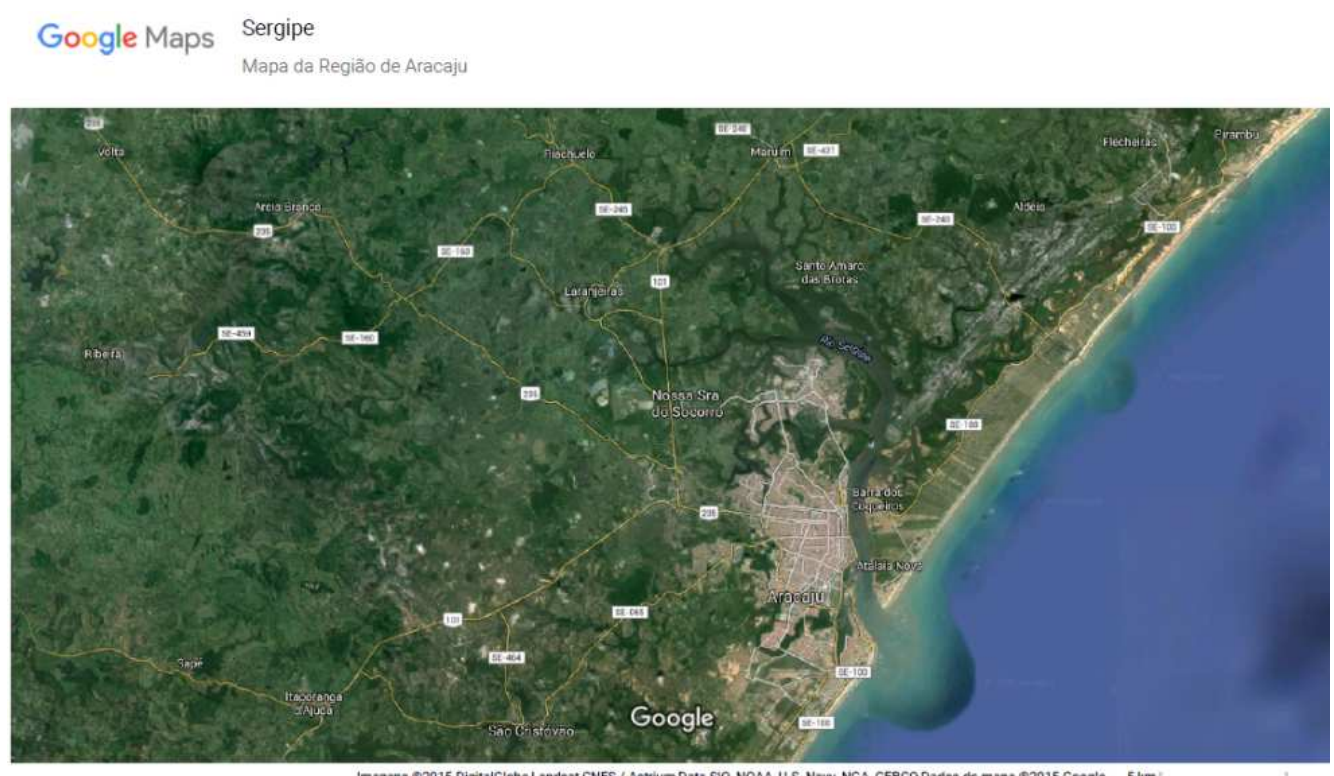
Além da vegetação de mangue, a região é rica em praias, dunas, restingas e manchas de floresta perenifólia hidrófila costeira. Os mangues compreendem todo o sistema estuarino do rio Sergipe resistindo à pressão exercida pela intensa ocupação em andamento desde o século XIX, fortemente acelerada nas três últimas décadas pelo crescimento de Aracaju e municípios vizinhos.

O clima da área pode ser descrito como quente e úmido, com pluviometria média de $1.200 \mathrm{~mm} / \mathrm{ano}$ e a região ainda pode ser caracterizada pela planície litorânea deltaica, estuarina com praias, sendo em algumas partes aterrada para a implantação urbana igualmente o que vem acontecendo com os mangues.

O Estado de Sergipe situa-se entre o Estado de Alagoas, ao norte, Estado da Bahia, ao sul e oeste, e entre o Oceano atlântico ao leste. Temos na Figura 1, destacado em azul, o Estado de Alagoas, em vermelho o Estado de Sergipe e em roxo o Estado da Bahia.

A Figura 2 mostra a concentração populacional dos Municípios da região de Aracaju: Aracaju, Barra dos Coqueiros, Nossa Senhora do Socorro, Santo Amaro das Brotas, Laranjeiras, Maruim e São Cristóvão

\section{METODOLOGIA}

\section{Levantamento de dados}

Os dados levantados para o estudo da área, como dados populacionais, abastecimento de água, coleta de lixo e de rede de esgoto, foram tirados do Instituto Brasileiro de Geografia e Estatística (IBGE).

Os dados populacionais foram retirados do banco de dados do SIDRA (Sistema IBGE de Recuperação Automática) na seção demográfico e contagem na parte de series temporais, sendo a tabela utilizada a 202.

As informações sobre abastecimento de água, coleta de lixo e rede de esgoto foram retirados do mesmo banco de dados, sendo que foram encontradas na seção Censo Demográfico 2010 na subseção Universo - Características da População e dos Domicílios (tabelas 3263, 3217 e 3216 respectivamente) e na seção Censo Demográfico 2000 na subseção Universo (tabelas 1436, 1439 e 1437 respectivamente). 


\section{Analise de risco}

A metodologia utilizada para avaliar os riscos causados pela infraestrutura precária e o demasiado crescimento urbano da região estudada e como de que forma isso afeta o ecossistema de mangue, foi pela Análise Preliminar de Perigo (APP). Essa metodologia é um método intuitivo que visa identificar possíveis ameaças decorrentes deprocessos (ALMEIDA et al., 2008).

Então para conseguir elaborar a tabela de análise preliminar de perigo (Tabela 6) assumiu-se como indicadores de pressão o crescimento populacional urbano e a infraestrutura precária da região, sendo um dos indicadores de estado os ecossistemas de mangue da região que encontram-se sofrendo impactosambientais gerados pelos indicadores de pressão.

Para conseguir analisar o risco foram utilizadas tabelas baseadas no trabalho de Almeida (2008) (Tabela 1, 2 e 3).

Tabela 1: Categorias de Frequências

\begin{tabular}{cccc}
\hline Categoria & Denominação & Frequência (anual) & Descrição \\
\hline A & Extremamente remota & $\mathrm{F}<10^{-4}$ & Possível mais extremamente improvável \\
B & Remota & $10^{-4}<\mathrm{F}<10^{-3}$ & Não esperado \\
C & Improvável & $10^{-3}<\mathrm{F}<10^{-2}$ & Pouco provável de ocorrer \\
D & Provável & $10^{-2}<\mathrm{F}<10^{-1}$ & Esperado ocorrer uma vez durante a \\
& & & vida útil da instalação \\
E & Frequente & & Esperado ocorrer várias vezes durante \\
& & & a vida útil da instalação \\
\hline
\end{tabular}

Fonte: ALMEIDA, 2008.

Tabela 2: Categorias de Severidades

\begin{tabular}{ccc}
\hline Categorias & Denominação & Descrição/Características \\
\hline I & Desprezível & Sem danos ou danos insignificantes \\
II & Marginal & Danos leves controláveis \\
III & Critica & Danos severos. Exige ações corretivas \\
& & imediatas \\
IV & Catastrófica & Danos irreparáveis ou de lenta \\
& & recuperação \\
\hline
\end{tabular}

Fonte: ALMEIDA, 2008. 
Tabela 3: Matriz de Classificação de Riscos - Frequência X Severidade

\begin{tabular}{cccccc}
\hline & A & B & C & D & E \\
\hline IV & Menor & Moderado & Sério & Critico & Critico \\
III & Desprezível & Menor & Moderado & Sério & Critico \\
II & Desprezível & Desprezível & Menor & Moderado & Sério \\
I & Desprezível & Desprezível & Desprezível & Menor & Moderado \\
\hline
\end{tabular}

Fonte: ALMEIDA, 2008.

\section{RESULTADOS E DISCUSSÕES}

O crescimento populacional da região se depara entre um aumento moderado a elevado, possuindo uma taxa de crescimento de $15,6 \%$ e 7,69\% para o município de Nossa Senhora do Socorro nos anos de 1991 e 2000 respectivamente. A região também apresenta uma densidade urbana de valores medianos a altos, sendo em Aracaju superior a 3.000 hab. $/ \mathrm{km}^{2} \mathrm{em} 2010$.

Matos (2010) em seu estudo relata que em 1970 Aracaju apresentava a terceira maior população urbana do Nordeste perdendo apenas para Salvador e Recife e que essa rápida urbanização destoava do ritmo urbanístico do próprio estado de Sergipe. Nesse período a população urbana de Aracaju era aproximadamente quase $98 \%$ estando um pouco destoante dos outros municípios que possuíam nesse mesmo período um percentual de população urbana inferior a 70\% (Tabela 4). E perante a essa rápida urbanização, em 1991 Aracaju já possuía uma população inteiramente urbana.

Em 2000 a taxa de crescimento populacional do município de Aracaju diminuiu abruptamente em relação ao ano anterior da pesquisa, 1991, acreditando-se que a responsabilidade por este evento deve-se em parte as mudanças demográficas ocorridas no Brasil durante aquele momento, como a redução na da taxa de natalidade (MATOS, 2010). Além disso Aracaju já começava a apresentar sinais de lotação devido ao seu crescimento demográfico e somente quem poderia arcar com os custos mais elevados de vida, de moradia, transporte entre outros poderia garantir a reprodução (MATOS, 2010). 
Devido a esse alto custo de vida grande parte do excesso populacional de Aracaju é deslocado para os municípios mais próximos, ou seja, a população vai principalmente para os municípios de Barra dos Coqueiros, Nossa Senhora do Socorro e São Cristóvão (MATOS, 2010), sendo estes os municípios da Região de Aracaju que tiveram maior taxa de crescimento populacional em 2000 (Tabela 4).

Tabela 4: Comparação de dados demográficos na Região de Aracaju

\begin{tabular}{|c|c|c|c|c|c|c|c|c|}
\hline Ano & $\begin{array}{c}\text { Região de } \\
\text { Aracaju }\end{array}$ & Aracaju & $\begin{array}{l}\text { Barra dos } \\
\text { Coqueiros }\end{array}$ & $\begin{array}{c}\text { Nossa } \\
\text { Senhora } \\
\text { do } \\
\text { Socorro }\end{array}$ & $\begin{array}{c}\text { Santo } \\
\text { Amaro } \\
\text { das } \\
\text { Brotas }\end{array}$ & Laranjeiras & Maruim & $\begin{array}{c}\text { São } \\
\text { Cristóvão }\end{array}$ \\
\hline \multirow{4}{*}{1970} & $\begin{array}{l}\text { População } \\
\text { total }\end{array}$ & 183.670 & 5.568 & 9.346 & 5.415 & 10.627 & 9.233 & 20.409 \\
\hline & $\%$ Urbana & 97,61 & 64,73 & 16,64 & 45,37 & 43,04 & 67,56 & 49,98 \\
\hline & $\begin{array}{c}\text { Taxa de } \\
\text { crescimento }\end{array}$ & - & - & - & - & - & - & - \\
\hline & $\begin{array}{l}\text { Densidade } \\
\left(\text { Hab./km²) }^{2}\right.\end{array}$ & $1.009,97$ & 61,65 & 59,62 & 23,13 & 65,49 & 98,46 & 46,72 \\
\hline \multirow{4}{*}{1980} & $\begin{array}{l}\text { População } \\
\text { total }\end{array}$ & 293.119 & 7.952 & 13.710 & 7.947 & 13.275 & 11.366 & 24.129 \\
\hline & $\%$ Urbana & 98,22 & 69,38 & 11,68 & 67,74 & 49,54 & 74,54 & 48,63 \\
\hline & $\begin{array}{c}\text { Taxa de } \\
\text { crescimento }\end{array}$ & - & - & - & - & - & - & - \\
\hline & $\begin{array}{l}\text { Densidade } \\
\left(\mathbf{H a b} / \mathbf{k m}^{2}\right)\end{array}$ & $1.611,81$ & 88,04 & 87,45 & 33,94 & 81,80 & 121,21 & 55,23 \\
\hline \multirow{4}{*}{1991} & $\begin{array}{l}\text { População } \\
\text { total }\end{array}$ & 402.341 & 12.727 & 67.574 & 10.624 & 18.944 & 14.683 & 47.558 \\
\hline & $\%$ Urbana & 100 & 58,47 & 99,91 & 72,69 & 84,57 & 75,63 & 97,21 \\
\hline & $\begin{array}{c}\text { Taxa de } \\
\text { crescimento }\end{array}$ & $2,92 \%$ & $4,37 \%$ & $15,60 \%$ & $2,67 \%$ & $3,29 \%$ & $2,36 \%$ & $6,36 \%$ \\
\hline & $\begin{array}{l}\text { Densidade } \\
\left(\mathbf{H a b} / \mathbf{k m}^{2}\right)\end{array}$ & $2.212,40$ & 140,91 & 431,04 & 45,37 & 116,74 & 156,58 & 108,86 \\
\hline
\end{tabular}




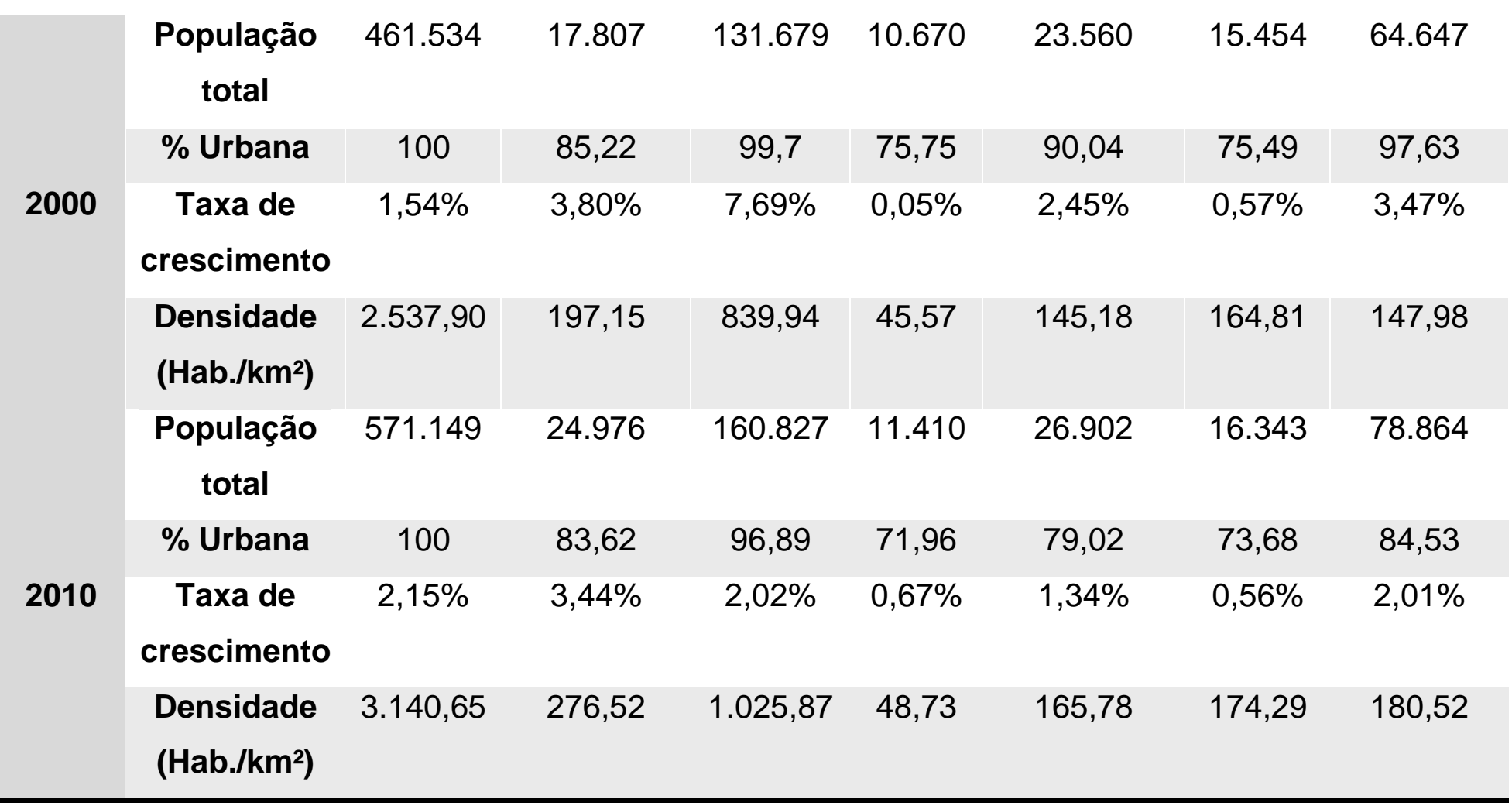

\section{Fonte: IBGE}

Almeida e Barbieri (2008) evidenciam que a costa de Sergipe é uma importante região utilizada por algumas espécies de aves que demostraram grande vínculo com os ecossistemas de mangues. E dentre a avifauna observada houve um destaque maior para uma espécie que se encontra na lista de animais ameaçados de extinção, sendo os principais riscos para essa espécie a destruição do mangue e os altos índices de poluição da água por efluentes domésticos.

Assim, apesar do demasiado crescimento urbano na Região de Aracaju muitas residências vêm sendo construídas sem qualquer infraestrutura inclusive sem esgotamento sanitário (FRANÇA e REZENDE, 2010), o que explica a distribuição da rede de esgoto atingir menos de $70 \%$ dos domicílios nos restos das regiões excluindo unicamente Aracaju, tendo mesmo este uma distribuição inferior a $80 \%$ (Tabela 5). E esse esgoto não tratado acaba contribuindo para a contaminação da água ameaçando assim não somente a qualidade de vida da população como a degradação ambiental (FRANÇA e REZENDE, 2010; ALMEIDA e BARBIERI, 2008). 
Entre os municípios desta região somente Santo Amaro das Brotas apresentou uma carência maior nos serviços de rede de água e coleta de lixo, possuindo um atendimento destes serviços inferior a 70\%. E Santo Amaro também foi o município a apresentar a situação mais precária de distribuição de rede de esgoto possuindo um valor percentual inferior a 4\% em 2010 (Tabela 5).

Os municípios vizinhos ao município de Aracaju, Barra dos Coqueiros, Nossa Senhora do Socorro, Santo Amaro das Brotas, Laranjeiras, Maruim e São Cristóvão, não conseguem acompanhar os valores de distribuição de rede de esgoto, abastecimento de água e coleta de lixo, pois são compostos por uma população de renda mais baixa os quais foram "empurrados" para as cidades vizinhas devido ao alto valor do custo de vida da capital levantando assim moradias deficientes de infraestrutura básica(MATOS, 2010).

Tabela 5: Percentual de Serviços Públicos instalados na Região de Aracaju

\begin{tabular}{|c|c|c|c|c|c|c|c|c|}
\hline & $\begin{array}{l}\text { Região } \\
\text { de } \\
\text { Aracaju }\end{array}$ & Aracaju & $\begin{array}{l}\text { Barra dos } \\
\text { Coqueiros }\end{array}$ & $\begin{array}{c}\text { Nossa } \\
\text { Senhora } \\
\text { do } \\
\text { Socorro }\end{array}$ & $\begin{array}{c}\text { Santo } \\
\text { Amaro } \\
\text { das } \\
\text { Brotas }\end{array}$ & Laranjeiras & Maruim & $\begin{array}{c}\text { São } \\
\text { Cristóvão }\end{array}$ \\
\hline \multirow{3}{*}{2010} & $\begin{array}{c}\text { Rede } \\
\text { geral de } \\
\text { esgoto }\end{array}$ & 71,57 & 26,18 & 49,88 & 3,73 & 22,85 & 54,89 & 25,31 \\
\hline & $\begin{array}{c}\text { Rede } \\
\text { geral de } \\
\text { água }\end{array}$ & 97,91 & 78,43 & 94,39 & 63,2 & 73,43 & 71,23 & 81,04 \\
\hline & $\begin{array}{l}\text { Coleta } \\
\text { de lixo }\end{array}$ & 99,03 & 81,74 & 92,01 & 68,64 & 75,59 & 73,5 & 76,29 \\
\hline \multirow{2}{*}{2000} & $\begin{array}{c}\text { Rede } \\
\text { geral de } \\
\text { esgoto }\end{array}$ & 56,38 & 7,32 & 46,17 & 0,59 & 11,64 & 41,12 & 22,05 \\
\hline & $\begin{array}{c}\text { Rede } \\
\text { geral de } \\
\text { água }\end{array}$ & 95,74 & 79,43 & 92,23 & 61,2 & 63,88 & 68,27 & 83,1 \\
\hline
\end{tabular}




\begin{tabular}{llllllll}
\hline $\begin{array}{l}\text { Coleta } \\
\text { de lixo }\end{array}$ & 95,95 & 80,53 & 80,12 & 68,75 & 63,59 & 71,27 & 46,17 \\
\hline
\end{tabular}

Fonte: IBGE

Como já elucidado ao longo deste artigo o crescimento desenfreado da capital de Sergipe, Aracaju, é um dos motivos para ocorrência de ocupações irregulares, tanto as que ocorrem no próprio município como nos municípios vizinho a este. Alguma dessas moradias situam-se perto de áreas de manguegerando contaminação do ecossistema por meio de despejos de efluentes domésticos, sendo esta a principal forma de degradar esse frágil ecossistema, e além desse agravante algumas habitações fazem aterramento do manguezal perdendo assim os recursos naturais que poderiam ser oferecidos por ele.

Então a partir da tabela 6 pode-se avaliar a gravidade de alguns perigos gerados pelo crescimento urbano, ocupações irregulares e pela infraestrutura deficiente, como também comentar algumas formas de prevenir e minimizar que determinadas consequências ocorram ou que se agravem.

Tabela 6: Resultados da Análise Preliminar de Perigo (APP)

\begin{tabular}{|c|c|c|c|c|c|c|}
\hline \multicolumn{7}{|c|}{ Análise Preliminar de Perigo (APP) } \\
\hline Perigo & Causa & Consequência & Frequência & Severidade & Risco & Recomendações \\
\hline $\begin{array}{l}\text { Ocupações } \\
\text { irregulares }\end{array}$ & $\begin{array}{c}\text { Crescimento } \\
\text { urbano } \\
\text { acelerado }\end{array}$ & $\begin{array}{c}\text { Infraestrutura } \\
\text { básica deficiente } \\
\text { favorecendo a } \\
\text { contaminação } \\
\text { por esgoto }\end{array}$ & D & II & Moderado & $\begin{array}{c}\text { Investir em } \\
\text { planejamento urbano } \\
\text { que vise controlar o } \\
\text { crescimento } \\
\text { populacional nessas } \\
\text { áreas }\end{array}$ \\
\hline $\begin{array}{c}\text { Aterro e/ou } \\
\text { desmatamento } \\
\text { do manguezal }\end{array}$ & $\begin{array}{l}\text { Ocupações } \\
\text { irregulares }\end{array}$ & $\begin{array}{l}\text { Perda dos ativos } \\
\text { ambientais, da } \\
\text { fauna e da flora } \\
\text { desse } \\
\text { ecossistema }\end{array}$ & C & II & Menor & $\begin{array}{l}\text { Recuperar a área } \\
\text { degradada e impedir } \\
\text { a ocupação de } \\
\text { moradias sob estas } \\
\text { condições }\end{array}$ \\
\hline $\begin{array}{l}\text { Poluição dos } \\
\text { mangues por } \\
\text { efluentes }\end{array}$ & $\begin{array}{l}\text { Ocupações } \\
\text { irregulares }\end{array}$ & $\begin{array}{c}\text { Perda de } \\
\text { animais } \\
\text { silvestres e de }\end{array}$ & E & II & Sério & $\begin{array}{c}\text { Controle e } \\
\text { monitoração dos } \\
\text { efluentes líquidos que }\end{array}$ \\
\hline
\end{tabular}




\begin{tabular}{|c|c|c|c|c|c|c|}
\hline domésticos & & $\begin{array}{c}\text { flora típica desse } \\
\text { ecossistema }\end{array}$ & & & & $\begin{array}{l}\text { aportam através de } \\
\text { dutos e } \\
\text { implementação de } \\
\text { programa de } \\
\text { saneamento }\end{array}$ \\
\hline $\begin{array}{c}\text { Contaminação } \\
\text { de qualquer } \\
\text { ecossistema } \\
\text { por esgoto }\end{array}$ & $\begin{array}{c}\text { Infraestrutura } \\
\text { básica } \\
\text { precária }\end{array}$ & $\begin{array}{c}\text { Perda de } \\
\text { animais } \\
\text { silvestres e de } \\
\text { flora típica desse } \\
\text { ecossistema }\end{array}$ & $E$ & II & Sério & $\begin{array}{c}\text { Controle e } \\
\text { monitoração dos } \\
\text { efluentes líquidos que } \\
\text { aportam através de } \\
\text { dutos e } \\
\text { implementação de } \\
\text { programa de } \\
\text { saneamento }\end{array}$ \\
\hline
\end{tabular}

Fonte: confecção própria

\section{CONCLUSÃO}

Foi possível perceber através da análise da tabela 5 que os municípios têm que objetivar proporcionar melhores condições de vida para a sua população a partir de serviços básicos, como abastecimento de água, coleta de lixo e rede de esgoto. Além de buscar conciliar a valoração dos ecossistemas com a sua preservação, visto que os manguezais podem desempenhar várias funções como atividades de ecoturismo e de pesquisa, refúgio de animais e dispersão de sementes (WANDERLEY e WANDERLEY, 2003).

De acordo com Wanderley e Wanderley (2003) deve-se evitar ocupações em áreas frágeis, como em locais apontados como não arquitetáveis e em áreas merecedoras de proteção. Então para isso recomenda-se que haja um rigoroso controle da ocupação assim como um severo controle e monitoramento dos efluentes domésticos para que estes não prejudiquem mais os ecossistemas.

Seria também aconselhável que cada município investisse em campanhas de educação ambiental, visto que as condições de abastecimento de água, coleta de lixo e rede de esgoto são muito precárias, até mesmo na capital de Sergipe, e o crescimento populacional dos municípios só tendem a aumentar, mesmo havendo lotação populacional, o que leva a agravar o quadro. Então conscientizar a população seria ótimo passo, visto que se cada indivíduo fizesse 
sua parte os índices desses serviços básicos poderiam melhorar agredindo assim com menos impacto o meio ambiente.

\section{REFERÊNCIAS}

ALMEIDA, B. J. M.;BARBIERI, E. Biodiversidade das aves do manguezal da 13 de julho em Aracaju, Sergipe. O Mundo da Saúde, 32(3), 317-328, 2008.

ALMEIDA, J.R.;LINS, G.A.;AGUIAR, L.A.;AQUINO, A.R.;EGUTE, N.S.Análise de risco ambiental em estacoes de tratamento de esgotos (ETE) utilizando a análise preliminar de perigo (APP). Rev. Bras. Pesq. Des. - Vol. 10 - n² - Agosto 2008

FRANÇA, S. L. A.;REZENDE, V. F. Conflitos ambientais e ocupação da zona de expansão urbana de Aracaju: distanciamento de uma prática sustentável. V Encontro Nacional da Anppas, 4,2010.

INSTITUTO BRASILEIRO DE GEOGRAFIA E ESTATÍSTICA (IBGE) - Cidades: Sergipe. Disponível em: <http://www.cidades.ibge.gov.br/xtras/uf.php?lang=\&coduf=28\&search=sergipe>. Acesso em: 27 de novembro de 2015.

LIMA, A.V.O. Degradação dos manguezais do município de Aracaju emdecorrência da urbanização. Anais XVI Encontro Nacional dos Geógrafos, 2010.

MATOS, E. N. Dinâmica econômica, processo de urbanização e mercado de trabalho: o caso de Aracaju (1970-2005), 2010.

MINISTÉRIO DO MEIO AMBIENTE (MMA).Primeiro Relatório Nacional para a Conservação sobre Diversidade Biológica.Brasília, DF:MMA, 1998. 
OLIVEIRA, K.E.J;RODRIGUES, A.J. Impactos ambientais no manguezal do bairro treze de julho, 2012.

WANDERLEY, L.L., WANDERLEY, M.L. Gestão ambiental e urbanização: o zoneamento ecológico-econômico da zona de expansão de Aracaju, capital do estado de Sergipe-Brasil.In: IX Congresso da Associação Brasileira de Estudos do Quaternário/II Congresso do Quaternário de Países de Línguas Ibéricas/II Congresso sobre Planejamento e Gestão da Zona Costeira dos Países de Expressão Portuguesa. Recife, 2003. 